\title{
Çocuklarda Görülen Saç ve Saçlı Deri Hastalıklarının Değerlendirilmesi
}

\author{
Evaluation of the Hair and Scalp Diseases in Children
}

\author{
๑Atiye Akbayrak, ¿Zennure Takçı
}

1 Gaziosmanpaşa Üniversitesi, Tıp Fakültesi, Deri ve Zührevi Hastalıkları Anabilim Dalı, Tokat, Türkiye

\section{ÖZ}

Amaç: Çocuklardaki saç ve saçılı deri hastalıkları geniş bir yelpazede incelenir. Bu çalışmanın amacı, çocukluk döneminde görülen saç ve saçlı deri hastalıklarının değerlendirilmesidir.

Gereç ve Yöntem: Bu retrospekitf çalışmada, Şubat 2015 ile Şubat 2018 tarihleri arasında dermatoloji polikliniğine başvuran 18 yaş altı hastalara ait 5385 dosya incelendi. Saç veya saçlı deri hastalığı olan ve verilerinde eksiklik bulunmayan 546 hasta çalışmaya dahil edildi.

Bulgular: Beş bin üç yüz seksen beş hastanın 546'sında (\%10.13) saç ve saçı deri hastalığı vardı. Hastaların (337 kız ve 209 erkek) yaş ortalaması $11.77 \pm 4.34$ yıl (1 ay-17 yıl) idi. Saptanan saç ve saçlı deri hastalığı çeşidi 12 , skatrisyel alopesi nedeni olan hastalık oranı \%1.83 idi. Seboreik dermatit, alopesi areata, telojen effluvium, pitiriyazis kapitis simpleks, psoriazis ve tinea kapitis en sık saptanan hastalıklardı (sırasıyla, \%33.2, $\% 15.9, \% 14.1, \% 12.3, \% 10.8$ ve \%7.7). Pitiriyazis kapitis simpleks ve telojen effluvium erkeklere kıyasla kızlarda; alopesi areata, tinea kapitis ve androgenetik alopesi kızlara kıyasla erkeklerde anlamlı oranda yüksekti $(p<0.05)$. Seboreik dermatit, telojen effluvium ve androgenetik alopesi 12 yaş üstünde; pitiriyazis amiantase, alopesi areata ve tinea kapitis 12 yaş altında anlamlı oranda yüksekti $(p<0.05)$.

Sonuç: Çocukluk döneminde en sık görülen saç ve saçlı deri hastalıkları, seboreik dermatit, alopesi areata ve telojen effluviumdu. Hastalık görülme sıklık ve oranları yaş ve cinsiyete göre değişmekteydi. Saç ve saçlı deri hastalıklarının erken tanı ve tedavisi çocukların büyüme ve psikolojik gelişimi üzerine olumlu katkı sağlayabilir.

Anahtar Kelimeler: Çocuk, saç, saçlı deri, saç hastalıkları, saç ve saçlı deri hastalıkları

\section{ABSTRACT}

Aim: The hair and scalp diseases in children are studied in a wide spectrum. The aim of this study is to evaluate the hair and scalp diseases during childhood.

Material and Method: In this retrospective study, the records of 5385 patients under 18 years of age, who were admitted to dermatology outpatient clinic between February 2015 and February 2018, were screened. Five hundred and forty six patients having hair and scalp diseases, without any missing information, were included in the study.

Results: Of 5385 patients, 546 (10.13\%) had hair and scalp diseases. The mean age of patients (337 females and 209 males) were 11.77 \pm 4.34 years (1 months-17 years). There were 12 types of hair and scalp diseases. The rate of diseases causing cicatricial alopecia was 1.83\%. Seborrheic dermatitis, alopecia areata, telogen effluvium, pityriasis capitis simplex, psoriasis, and tinea capitis were the most common diseases $(33.2 \%, 15.9 \%$, $14.1 \%, 12.3 \%, 10.8 \%$, and $7.7 \%$, respectively). Pityriasis capitis simplex and telogen effluvium in females; alopecia areata, tinea capitis and androgenic alopecia in males were significantly higher $(p<0.05)$. Seborrheic dermatitis, telogen effluvium and androgenic alopecia in patients above 12 years of age; pityriasis amiantacea, alopecia areata and tinea capitis in patients under 12 years of age were significantly higher $(p<0.05)$.

Conclusion: The most frequent hair and scalp diseases were seborrheic dermatitis, alopecia areata, and telogen effluvium during childhood. Frequency and ratio of these diseases altered according to age and gender. Early diagnosis and treatment of these diseases may affect positively on growth and psycholocial development of children.

Keywords: Child, hair, scalp, hair disease, hair and scalp diseases 


\section{GIRIŞ}

Çocukluk döneminde görülen saç ve saçlı deri hastalıkları, geniş bir yelpaze oluşturmakta olup, etiyopatogenezinde emosyonel stres, mikrobiyal etkenler, genetik ya da çevresel etmenler ve sistemik hastalıklar gibi çok sayıda faktör rol alır. Bu hastalıklardan bazıları geri dönüşümsüz saç kaybıyla sonuçlanan skatrisyel alopesiye neden olabilir (1). Her iki cinste de güzellik algısının önemli bir parçası olan saçın, çocukluk döneminden itibaren sağlıklı gelişiminin sağlanması, ruhsal açıdan sağlıkı bireylerin yetişmesine katkı sağlayabilir. Bu çalışmanın amacı, çocukluk yaş grubunda sık görülen saç ve saçlı deri hastalıkları spektrum ve sıklığının değerlendirilmesidir.

\section{GEREÇ VE YÖNTEM}

Çalışmada, Şubat 2015 ile Şubat 2018 tarihleri arasında üçüncü basamak bir sağlık kuruluşunun dermatoloji polikliniğine başvuran 18 yaş altı hastalara ait 5385 dosya (2533 erkek, $2852 \mathrm{kIz}$ ) retrospektif olarak tarandı. Verilerinde eksiklik bulunmayan ve saç ve saçlı deri hastalı̆̆ı tanısı alan 546 hasta çalışmaya dahil edildi. Hastalık tanısına ulaşmada uygulanan metod (klinik muayene, nativ preparat, histopatolojik inceleme) kaydedildi. Hastaların demografik özellikleri kaydedildi ve hastalar yaşlarına göre 2 yaş ve altı (infantil dönem), 3-5 yaş (okul öncesi dönem), 6-11 yaş (okul dönemi)ve 12 yaş ve üzeri (adölesan dönem) olmak üzere 4 gruba ayrıldı (2).

Çalışma öncesi etik kurul onayı alındı (18-KAEK-072).

\section{İstatistiksel analiz}

Sayısal veriler ortalama ve standart sapma olarak, kategorik veriler ise sayı ve yüzde olarak gösterildi. Yaş gruplarına ve cinsiyete göre hastalıkların dağılımlarının karşılaştırılmasında Ki-kare ve Fisher's exact testleri kullanıldı. Veriler Statistical Package for Social Sciences (SPSS Inc., Chi, IL) programı versiyon 20 programı ile analiz edildi. Tüm analizlerde istatistiksel anlamlılık $\mathrm{p}<0.05$ olarak kabul edildi.

\section{BULGULAR}

Değerlendirmeye alınan 5385 hasta dosyasının (2533 erkek, 2852 kız) 546'sında (\%10.13) saç ve saçlı deri hastalığı saptandı. Bu hastaların 337'si (\%61.7) kız, 209'u (\%38.3) erkekti. Erkeklerde saç ve saçlı deri hastalığı oranı \%13.3 iken, kızlarda \%7.33 idi. Hastaların yaşları 1 ay ile 17 yıl arasında değişmekte olup, yaş ortalaması $11.77 \pm 4.34$ yıl idi. Hastaların 42'sinde (\%7.7) tanıya nativ preparat; $39^{\prime}$ unda $(\% 7,1)$ histopatolojik inceleme; $465^{\prime}$ inde $(\% 85,2)$ klinik bulgularla ulaşıldığı gözlendi. Toplamda 12 çeşit saç ve saçlı deri hastalığı saptanmış olup, bunlar içerisinde skatrisyel alopesi nedeni olan hastalık tanısı alan hasta sayısı 10 (\%1.83) idi. Bu hastalardan 2'si (\%0.36) liken planopilaris, 8'i (\%1.47) tinea kapitis profunda tanilıydı.
En sık saptanan hastalıklar sıklık sırasına göre; seboreik dermatit, alopesi areata, telojen effluvium, pitiriyazis kapitis simpleks, psoriazis ve tinea kapitis (sırasıyla, \%33.2, $\% 15.9, \% 14.1, \% 12.3, \% 10.8$ ve \%7.7) idi. Cinsiyete göre hastalıkların dağılımı değerlendirildiğinde, pitiriyazis kapitis simpleks ve telojen effluvium kızlarda; alopesi areata, tinea kapitis ve androjenik alopesi erkeklerde istatistiksel olarak anlamlı düzeyde yüksekti $(p<0.05)$. Hastalıkların cinsiyete göre dağılımı Tablo 1'de özetlendi.

Hastaların 316'sı (\%57.9) 12 yaş ve üzeriydi. Seboreik dermatit, telojen effluvium ve androgenetik alopesi 12 yaş ve üzeri grupta anlamlı düzeyde yüksek saptanırken $(p<0.05)$; pitriyazis amiantase, alopesi areata ve tinea kapitis 12 yaş altı grupta anlamlı düzeyde yüksekti $(p<0.05)$. Ayrıca, alopesi areata ve tinea kapitis vakalarının çoğunluğu 6-11 yaş aralığında idi. Hastalıkların yaş gruplarına göre dağılımı Tablo 2'de özetlendi.

\begin{tabular}{|c|c|c|c|}
\hline Hastalık Adı & $\mathrm{K} \mathbf{\prime z}(\mathrm{n} / \%)$ & Erkek (n/\%) & Toplam (n/\%) \\
\hline Seboreik dermatit & $118 / 21,6$ & $63 / 11,5$ & $181 / 33,2$ \\
\hline Alopesi areata & $33 / 6$ & $54 / 9,9$ & $87 / 15,9$ \\
\hline Telojen effluvium & $64 / 11,7$ & $13 / 2,4$ & $77 / 14,1$ \\
\hline Pitiriyazis kapitis simpleks & $50 / 9,2$ & $17 / 3,1$ & $67 / 12,3$ \\
\hline Psoriazis & $39 / 7,1$ & $20 / 3,7$ & $59 / 10,8$ \\
\hline Tinea kapitis & $15 / 2,7$ & $27 / 4,9$ & $42 / 7,7$ \\
\hline Pitriyazis amiantase & $12 / 2,2$ & $4 / 0,7$ & $16 / 2,9$ \\
\hline Androgenetik alopesi & $1 / 0,2$ & $7 / 1,3$ & $8 / 1,5$ \\
\hline Trikotillomani & $3 / 0,5$ & $2 / 0,4$ & $5 / 0,9$ \\
\hline Liken planopilaris & $1 / 0,2$ & $1 / 0,2$ & $2 / 0,4$ \\
\hline $\begin{array}{l}\text { Genetik hastalıkları bağlı } \\
\text { saç bozukluğu }\end{array}$ & $1 / 0,2$ & $1 / 0,2$ & $2 / 0,4$ \\
\hline Toplam & $337 / 61,7$ & $209 / 38,3$ & $546 / 100$ \\
\hline
\end{tabular}

\section{TARTIŞMA}

Güzellik algısının önemli bir parçası olan saç ve bunun yatağı konumundaki saçlı deri ile ilgili hastalıklar, ruhsal ve bedensel olarak sağlıklı bir birey olma yolunda ilerleyen çocukları, neden olduğu psikolojik etkilerle olumsuz yönde etkileyebilir. Saç hastalıkları, çocukluk çağında dermatoloji poliklinik müracatına neden olan hastalıklar içinde küçük bir oranı oluştursa da, potansiyel sonuçları itibariyle önemli bir grup hastalıktır. Yıldız Seçkin ve ark (3) tarafından Tokat bölgesindeki 5043 çocuk hastada görülen deri hastalıkları prevalansının değerlendirildiği çalışmada, saç hastalıklarının görülme oranı \%4.4 olarak bildirilmiştir. Can ve ark nın (2) İstanbul bölgesindeki 850 çocukhastayı değerlendirdiği çalışmalarında ise bu oranın \%3.8 olduğu değerlendirilmiştir. Bu çalışmada saç ve saçlı deri hastalığı görülme oranı \%10.13 olarak saptanmış olup, bu yüksekliğin çalışmada, diğer çalışmalardan farklı olarak saçlı deri hastalıklarının (ekzema, papüloskuamlı hastalıklar, enfeksiyon gibi) değerlendirmeye alınmasıyla ilgili olduğu düşünüldü. 


\begin{tabular}{|c|c|c|c|c|c|c|}
\hline Hastalık adı & $\begin{array}{c}\text { Hasta } \\
\mathrm{n} / \%\end{array}$ & $\begin{array}{c}\text { Dosya } n=5385 \\
\%\end{array}$ & $\begin{array}{c}\leq 2 \text { yaş } \\
n / \%\end{array}$ & $\begin{array}{c}\text { 3-5 yaş } \\
\text { n/\% }\end{array}$ & $\begin{array}{c}\text { 6-11 yaş } \\
n / \%\end{array}$ & $\begin{array}{c}\geq 12 \text { yaş } \\
n / \%\end{array}$ \\
\hline Seboreik dermatit & $181 / 33.2$ & 3.36 & $6 / 1.1$ & $15 / 2.7$ & $26 / 4.8$ & $134 / 24.5$ \\
\hline Alopesi areata & $87 / 15.9$ & 1.61 & $1 / 0.2$ & $11 / 2$ & $46 / 8.4$ & $29 / 5.3$ \\
\hline Telojen effluvium & $77 / 14.1$ & 1.42 & - & $2 / 0.4$ & $19 / 3.5$ & $56 / 10.3$ \\
\hline $\begin{array}{l}\text { Pitiriyazis kapitis } \\
\text { simpleks }\end{array}$ & $67 / 12.3$ & 1.24 & - & $3 / 0.5$ & $26 / 4.8$ & $38 / 7$ \\
\hline Psoriazis & $59 / 10.8$ & 1.09 & - & $2 / 0.4$ & $25 / 4.6$ & $32 / 5.9$ \\
\hline Tinea kapitis & $42 / 7.7$ & 0.77 & - & $12 / 2.2$ & $21 / 3.8$ & $9 / 1.6$ \\
\hline Pitiriyazis amiantase & $16 / 2.9$ & 0.29 & - & $8 / 1.5$ & $3 / 0.5$ & $5 / 0.9$ \\
\hline Androgenetik alopesi & $8 / 1.5$ & 0.14 & - & - & - & $8 / 1.5$ \\
\hline Trikotillomani & $5 / 0.9$ & 0.09 & - & - & $2 / 0.4$ & $3 / 0.5$ \\
\hline Liken planopilaris & $2 / 0.4$ & 0.03 & - & - & - & $2 / 0.4$ \\
\hline $\begin{array}{l}\text { Genetik hastalıkları } \\
\text { bağlı saç bozukluğu }\end{array}$ & $2 / 0.4$ & 0.03 & $1 / 0.2$ & - & $1 / 0.2$ & - \\
\hline Toplam & $546 / 100$ & 10.13 & $8 / 1.5$ & $53 / 9.7$ & $169 / 31$ & $316 / 57.9$ \\
\hline
\end{tabular}

Saç hastalıkları konjenital ya da akkiz sebeplerle ortaya çıkabilir ve klinik olarak diffüz ya da lokalize formda olabilir. Hastalık etiyopatogenezine ve yaptığı hasarın düzeyine göre skatrisyel (kalıcı) ya da nonskatrisyel (geri dönüşümlü) alopesiyle sonuçlanabilir. Emosyonel stres, hormonal nedenler, lokal ya da sistemik hastalıklar, beslenme ilişkili faktörler ya da immünolojik mekanizmalar etiyolojide rol oynayabilir. Çocuklarda görülen saç dökülmeleri sıklıkla nonskatrisyel ve akkiz nedenlidir (1). Bu çalışmada da skatisyel alopesi nedeni olan hastalık oranı \%1.83 olarak saptanmıştır. Ek olarak bu çalışmada 2 hastada gözlenen ve klinik olarak erken dönemde bulgu veren kıl şaft anomalileri sıklıkla ilk 1-3 yaşta tanı alır $(1,4)$.

Literatürde çocuklarda saç ve saçlı deriyi etkileyen hastalıklara ilişkin sınırlı sayıda çalışma mevcuttur. Türkiye'den Doğruk Kaçar ve ark nın (5) 159 çocuk hastanın saç ve saçlı deri hastalıklarını retrospektif olarak değerlendirildiği çalışmalarında, hastalık oranı \%6.02 olarak bildirilmiştir. Seboreik dermatit, alopesi areata, tinea kapitis, telojen effluvium ve psoriazis en sık saptanan hastalıklar olarak değerlendirilmiştir. Ayrıca erkeklerde en sık alopesi areata, kızlarda ise seboreik dermatit saptandığı bildirilmiştir. Bu çalışmada hastalık daha yüksek oranda saptanmış olup, buna yönelik verilerin geniş çaplı ve prospektif çalışmalarla genişletilmesinin faydalı olacağı düşünüldü. En sık saptanan hastalıklar Doğruk Kaçar ve ark nın (5) çalışma sonuçlarıyla benzer olmakla birlikte, pitiriyazis kapitis simpleks de ayrı bir grup olarak değerlendirilmiş ve bu çalışmada yüksek oranda gözlenmiştir. Ayrıca seboreik dermatit sadece kızlarda değil, erkeklerde de en sık görülen hastalık olurken, alopesi areatanın burada erkek cinsiyette ikinci sıklıkta gözlenen hastalık olduğu saptanmıştır. Doğruk Kaçar ve ark nın (5) çalışmasında cinsiyete göre yaş dağılım profili belirtilmemekle birlikte, bu çalışmada seboreik dermatitin her iki grupta da en sık gözlenen hastalık olma nedeninin, her iki cinsiyette de 12 yaş ve üzeri hasta oranının yüksek olmasıyla ilişkili olabileceğini düşünüyoruz. Sarıfakıoğlu ve ark nın (6) saç ve saçlı deri hastalığı olan ve \%64'ünün 2 yaş altı olduğu 69 çocuk hastayı değerlendirdiği prospektif çalışmalarında en sık saptanan hastalık, benzer şekilde, seboreik dermatit olarak bildirilmiştir. Ek olarak geçici neonatal saç dökülmesi, alopesi areata, temporal trianguler alopesi ve pitiriyazis amiantasenin de sık gözlenen hastalıklardan olduğu değerlendirilmiştir. Bu çalışmada 1 yaş altı hasta sayısı oldukça az olmakla birlikte, en sık görülen hastalığın benzer şekilde seboreik dermatit olduğu gözlendi.

Nijerya'dan 113 çocuk hastanın saç hastalıklarının değerlendirildiği bir çalışmada, en sık saptanan hastalıklar sırasıyla tinea kapitis (\%55), alopesi areata (\%38), psoriasis (\%4) ve telojen effluviyum (\%3) olarak bildirilmiştir (7). Çalışmada en sık saptanan hastalıklar içerisinde adölesan dönemde sık görülen seboreik dermatitin olmamasının, çalışmadaki hasta üst yaş sınırının 13 olmasıyla ilişkili olabileceğini düşünüyoruz. Hindistan'da 15 yaş ve altı 504 pediatrik hastanın saç ve saçlı deri hastalıklarının değerlendirildiği prospektif çalışmada ise, saç hastalığı oranı \%8.67 olarak saptanmış ve en sık görülen hastalıklar folikülit, fronkül, pedikülozis, alopesi areata ve tinea kapitis olarak bildirilmiştir (8). Çocukluk döneminde görülen saç ve saçlı deri hastalıklarının sıklık ve oranlarıyla ilgili bildirilen farklı veriler, çalışmalara dahil edilen hastalıklardaki farklılıklarla ilişkili olabileceği gibi, toplumların genetik özellikleri, çevresel faktörler, hijyen ve yaşam koşulları gibi faktörlerle de ilişkili olabilir.

En sık görülen saç hastalıklarından biri olan alopesi areatanın \%20'sinin pediatrik yaş grubunda olduğu ve özellikle okul öncesi dönemde pik yaptığına dair bildiriler bulunmakla birlikte, bu çalışmada alopesi areata en sık 6-11 yaş aralığında saptanmıştır $(6,9,10)$.

Tinea kapitis gelişmekte olan ülkelerde önemli ve yaygın bir saçlı deri hastalığıdır. Sıklıkla adölesan dönem öncesinde görüldüğü ve özellikle 3-7 yaş aralığında en sık gözlenen dermatofit enfeksiyonu olduğu bildirilmiştir (11). Bu çalışmada erkeklerde ikinci sıklıkta gözlenen hastalık olduğu ve preadölesan dönemdeki yoğunluğu dikkat çekicidir. 
Androjen düzeyiyle ilişkili olarak ortaya çıkan androgenetik alopesinin prepubertal dönemdeki en erken başlangıç yaşı 6 olarak bildirilmiştir $(12,13)$. Bu çalışmada androgenetik alopesili olgularını tamamının adölesan dönemde oluşu da literatürle uyumlu bir veri olarak değerlendirildi.

\section{Çalışmanın kısıtlılıkları}

Bu çalışmada bazı kısıtlılıklar mevcuttur. Öncelikle çalışma retrospektif dizaynda olduğundan dosya verilerinde eksiklik olan hastalar çalışmaya dahil edilemedi. İkinci olarak saç ve saçlı deriyi tutan hastalık spektrumu oldukça geniş olduğundan, diğer çalışmalarla kıyaslandığında, çalışmaya dahil edilen/edilmeyen hastalıklar açısından farklılıklar olabilir. Ayrıca, çalışmada neonatal ve süt çocukluğu dönemindeki vaka sayısı sınırlı olduğundan bu dönemde görülebilen veya bu döneme spesifik olan hastalıklara ilişkin yeterli veri sağlanamadı. Bunun yanısıra çalışmaya dahil edilen hasta grubu bir üniversite hastanesinin dermatoloji polikliniğine müracat eden hastalardan oluştuğundan sonuçlar tüm topluma genellenemeyebilir.

\section{SONUÇ}

Çocukluk çağında saç ve saçlı deriyi ilgilendiren hastalıklar oldukça geniş bir spektrum oluşturmakta olup, cinsiyet ve yaş gibi çeşitli etmenlere bağlı olarak farklılık gösterebilir. Hastalığın olası etiyolojik faktörünün saptanması ve etkin tedavisi ile kalıcı hasarların önüne geçmek, sağlıklı bireylerin gelişimi açısından önem arzeder.

\section{ETIK BEYANLAR}

Etik Kurul Onayı: Çalışma öncesi etik kurul onayı alındı (18-KAEK-072).

Aydınlatılmış Onam: Çalışma retrospektif olarak dizayn edildiği için hastalardan aydınlatılmış onam alınmamıştır.

Hakem Değerlendirme Süreci: Harici çift kör hakem değerlendirmesi.

Çıkar Çatışması Durumu: Yazarlar bu çalışmada herhangi bir çıkara dayalı ilişki olmadığını beyan etmişlerdir.

Finansal Destek: Yazarlar bu çalışmada finansal destek almadıklarını beyan etmişlerdir.

Yazar Katkıları: Yazarların tümü; makalenin tasarımına, yürütülmesine, analizine katıldığını ve son sürümünü onayladıklarını beyan etmişlerdir.

\section{KAYNAKLAR}

1. Mandt N, Vogt A, Blume-Peytavi U. Differential diagnosis of hair loss in children. J Dtsch Dermatol Ges 2004;2(6):399-411.
2. Can B, Kavala $M$, Türkoğlu Z, Zindancı İ, Südoğan S, Topaloğlu F. İstanbul bölgesinde çocukluk çağında görülen deri hastalıklarının prevalansı. Türkderm 2011;45(1):10-3.

3. Yıldız Seçkin H, Kalkan G, Baş Y. Tokat bölgesinde çocukluk çağında görülen deri hastalıklarının prevalansı. Gaziosmanpaşa Ûniversitesi Tıp Fakültesi Dergisi 2013;5(1):8-15.

4. Mirmirani $P$, Huang KP, Price VH. A practical, algorithmic approach to diagnosing hair shaft disorders. Int J Dermatol 2011;50(1):1-12.

5. Doğruk Kaçar S, Özuğuz P, Karaca Ş. Pediatrik yaş grubunda saç ve saç̧ı deri hastalıklarının değerlendirilmesi. Turk J Dermatol 2014;8(3):147-50.

6. Sarıfakioglu E, Yılmaz AE, Gorpelioglu C, Orun E. Prevalence of scalp disorders and hair loss in children. Cutis 2012;90(5):225-9.

7. Nnoruka EN, Obiagboso I, Maduechesi C. Hair loss in children in South-East Nigeria: common and uncommon cases. Int J Dermatol 2007;46(Suppl 1):18-22.

8. Nageswaramma S, Sarojini VL, Vani T, Madhuri S. A clinicoepidemiological study of pediatric hair disorders. Indian J Paediatr Dermatol 2017;18(2):100-3.

9. Nanda A, Al-Fouzan AS, Al-Hasawi F. Alopecia areata in children: a clinical profile. Pediatr Dermatol 2002;19(6):482-5.

10. Nanda A, Al-Hasawi F, Alsaleh QA. A prospective survey of pediatric dermatology clinic patients in Kuwait: an analysis of 10,000 cases. Pediatr Dermatol 1999;16:6-11.

11. Patel GA, Schwartz RA. Tinea capitis: still an unsolved problem? Mycoses 2011;54(3):183-8.

12. Gonzalez ME, Cantatore-Francis J, Orlow SJ. Androgenetic alopecia in the paediatric population: a retrospective review of 57 patients. Br J Dermatol 2010;163(2):378-85.

13. Tosti $A$, lorizzo $M$, Piraccini BM. Androgenetic alopecia in children: report of 20 cases. Br J Dermatol 2005;152(3):556-9. 